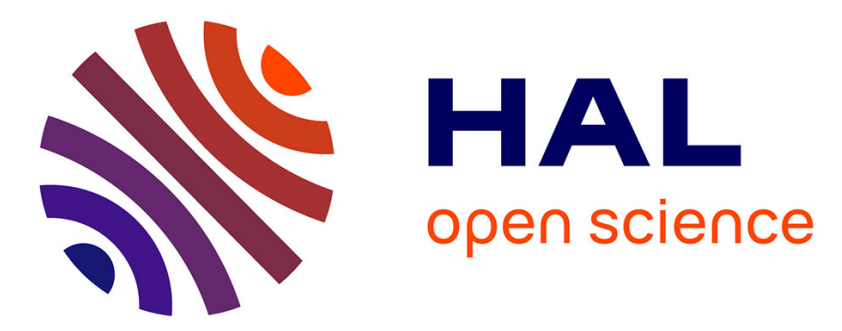

\title{
Multi-SISO Robust Crone Design for the Air Path Control of a Diesel Engine
}

Guillaume Colin, Patrick Lanusse, Abdellah Louzimi, Yann Chamaillard, Chao Deng, Dominique Nelson Gruel

\section{- To cite this version:}

Guillaume Colin, Patrick Lanusse, Abdellah Louzimi, Yann Chamaillard, Chao Deng, et al.. MultiSISO Robust Crone Design for the Air Path Control of a Diesel Engine. IFAC World Congress 2011, Aug 2011, Milan, Italy. pp.IFAC World Congress 2011. hal-00616614

\section{HAL Id: hal-00616614 https://hal.science/hal-00616614}

Submitted on 23 Aug 2011

HAL is a multi-disciplinary open access archive for the deposit and dissemination of scientific research documents, whether they are published or not. The documents may come from teaching and research institutions in France or abroad, or from public or private research centers.
L'archive ouverte pluridisciplinaire HAL, est destinée au dépôt et à la diffusion de documents scientifiques de niveau recherche, publiés ou non, émanant des établissements d'enseignement et de recherche français ou étrangers, des laboratoires publics ou privés. 


\title{
Multi-SISO Robust Crone Design for the Air Path Control of a Diesel Engine
}

\author{
G. Colin*, P. Lanusse**, A. Louzimi***, Y. Chamaillard*, C. Deng*, D. Nelson-Gruel** \\ * Laboratoire Pluridisciplinaire de Recherche en Ingénierie des Systèmes, Mécanique, Energétique (PRISME), EA4229 \\ University of Orléans, 8, rue Léonard de Vinci, 45072 Orléans, France \\ ** Université de Bordeaux, IPB, IMS CNRS UMR5218
}

Université Bordeaux 1, IMS-LAPS, 351 cours de la libération, 33405 Talence, France

\begin{abstract}
As a result of the increased complexity of today's powertrains, the traditional ways of designing engine control systems essentially through ad hoc methods and experimental tuning will no longer provide the desired level of performance. In this paper, the design of a multi-SISO robust controller is described which accommodates many of today's demands on controller development of the automotive industry. The control problem treated here is the air path control of a turbocharged diesel engine with Exhaust Gas Recirculation (EGR). Simulation results show the good control performance of the proposed control which is finally compared to an Internal Model Control.
\end{abstract}

Keywords: Engine control, Diesel engine, Robust control, MIMO system, Crone control design

\section{INTRODUCTION}

More stringent standards are being imposed to reduce the fuel consumption and pollutant emissions of compression ignition (CI) engines. Modern automobile engines must therefore meet the challenging, and often conflicting, goals of minimizing pollutant emissions and fuel consumption while satisfying driving performance over a wide range of operating conditions. This requires an "optimal" coordination of injection, turbocharger, and Exhaust Gas Recirculation (EGR) system under stationary and dynamic operation (Guzzella et al., 1998). From a control's point of view there are two important paths which have to be considered, namely: the fuel path and the air path (including EGR and turbocharger). In this paper, only the air path will be considered.

\subsection{System description}

The air intake of a turbocharged diesel engine, represented in Figure 1 can be described as follows. The compressor (pressure $p_{\text {boost }}$ ) produces a flow $Q_{\text {air }}$ from the ambient air. The compressor flow is cooled down by an intercooler and goes through the throttle $T h$ into the intake manifold (pressure $p_{\text {man }}$ ). At the exhaust side, the exhaust flow is split in three parts: the turbine flow, the wastegate flow and the EGR flow. The turbine flow powers up the turbine and through a shaft drives the compressor. Thus, the supercharging pressure $p_{\text {boost }}$ can be adjusted by the turbine flow which is controlled by the wastegate $W G$. The EGR flow which goes back into the intake manifold can be adjusted by the EGR valve.

The classical diesel engine control structure, as shown in Fig. 2 , is used here. The driver fixes the fuel mass (which is linked to the torque). From the fuel mass and the engine speed, the set points for boost pressure $p_{\text {boost } s p}$ and air flow
$\mathrm{Q}_{\text {air } s p}$ are then generated. In this paper, the throttle is statically controlled and will be taken into account in future works. Hence, considering the air path control, the manipulated variables are the wastegate and the EGR valve and the controlled variables are the supercharging pressure $p_{\text {boost }}$ and the air flow $Q_{\text {air }}$. The actuators have saturations which must be taken into account for the controller design.

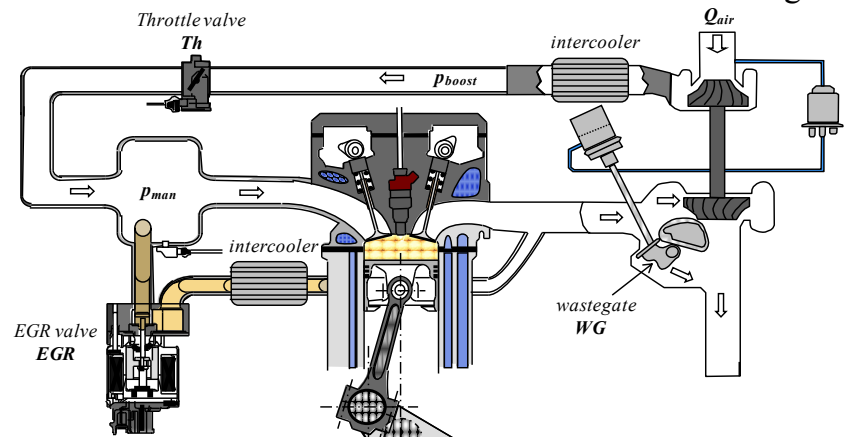

Fig. 1. Air path of a turbocharged diesel engine with Exhaust Gas Recirculation (EGR)

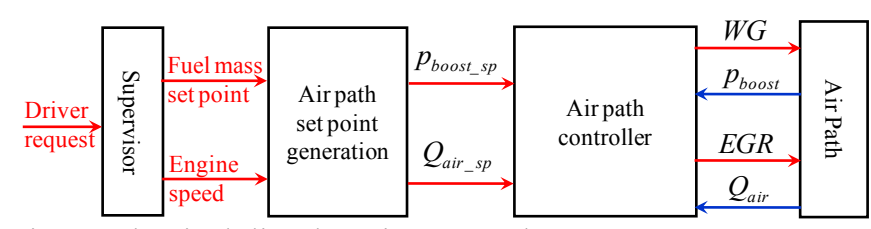

Fig. 2. Classical diesel engine control structure

\subsection{Control strategy}

While considering EGR and turbocharger control (i.e. without throttle control), some works can be found for the air path control of a diesel engine. Without being exhaustive, one can find these control methods applied to a diesel engine: Control Lyapunov Functions (Van Nieuwstadt et al., 2000; 
Jankovic and Kolmanovsky, 2000; Wahlström and Eriksson, $2008)$; Robust control and uncertainty parameterisation type (Jung et al., 2005); Nonlinear Internal Model Control (Nitsche et al, 2006); Gain scheduled control (Wei and del Re, 2007); Predictive control (Ortner and del Re, 2007; García-Nieto et al., 2008); Motion planning of the air and burned gas masses in the cylinder (Chauvin et al., 2008).

In the literature, robustness, fast tuning and low computational cost are not always ensured all together while these points are crucial for automotive applications. That is why, in this paper, we propose a method to design a computationally inexpensive robust control obtained faster and more systematically than the usual look-up-table based control, for a turbocharged diesel engine. Van Nieuwstadt et al. (1998) show that multivariable control design gives better results than decentralized control design for the air path control of a diesel engine. Hence, the idea in this paper is to investigate the multi-SISO Crone design, which is the design of a decentralized control that takes into account interactions of the full MIMO system.

Section 2 presents this multi-SISO Crone control design methodology. The system identification and the control design are detailed in Section 3. In the last part of the paper, controller implementation and results are shown on our calibrated simulation model.

\section{MULTI-SISO CRONE CONTROL DESIGN METHODOLOGY}

\subsection{SISO Crone design methodology}

The CRONE control-system design methodology is a frequency-domain approach developed since the eighties (Oustaloup et al., 1983, 1991, 1995; Lanusse, 1994; Åström, 1999). It is based on the common unity-feedback configuration. The principle of the third generation CRONE control methodology is to optimize the parameter of a nominal open-loop transfer function $\beta_{0}(s)$ that includes a band-limited complex fractional order integration:

$$
\beta_{0}(s)=\beta_{1}(s) \beta_{\mathrm{m}}(s) \beta_{\mathrm{h}}(s),
$$

- where $\beta_{\mathrm{m}}(s)$ is a set of band-limited generalized templates:

$$
\beta_{\mathrm{m}}(s)=\prod_{k=-N^{-}}^{N^{+}} \beta_{\mathrm{m} k}(s),
$$

with:

$\beta_{\mathrm{m} k}(s)=C_{k}^{\operatorname{sign}\left(b_{k}\right)}\left(\alpha_{k} \frac{1+s / \omega_{k+1}}{1+s / \omega_{k}}\right)^{a_{k}}\left(\Re e_{\mathrm{fi}}\left\{\left(\alpha_{k} \frac{1+s / \omega_{k+1}}{1+s / \omega_{k}}\right)^{\mathrm{i} b_{k}}\right\}\right)^{-q_{k} \operatorname{sign}\left(b_{k}\right)}$

$\alpha_{k}=\left(\omega_{k+1} / \omega_{k}\right)^{1 / 2}$ for $k \neq 0$ and $\alpha_{0}=\left(1+\left(\frac{\omega_{\mathrm{r}}}{\omega_{0}}\right)^{2} / 1+\left(\frac{\omega_{\mathrm{r}}}{\omega_{1}}\right)^{2}\right)^{1 / 2}$

- where $\beta_{1}(s)$ is an integer order $n_{1}$ proportional integrator and where $\beta_{\mathrm{h}}(s)$ is a low-pass filter of integer order $n_{\mathrm{h}}$ :

$$
\beta_{1}(s)=C_{\mathrm{l}}\left(\frac{\omega_{-N^{-}}}{s}+1\right)^{n_{1}}, \beta_{\mathrm{h}}(s)=C_{\mathrm{h}}\left(\frac{s}{\omega_{N^{+}}}+1\right)^{-n_{\mathrm{h}}}
$$

Gains $C_{\mathrm{x}}\left(C_{k}, C_{\mathrm{l}}\right.$ and $\left.C_{\mathrm{h}}\right)$ are such that $\omega_{\mathrm{r}}$ is the closed-loop resonant frequency. Order $n_{1}$ has to be set to manage the accuracy provided by the control-system. Order $n_{\mathrm{h}}$ has to be set to obtain a proper or bi-proper control. When it is useful, $N^{-}$and $N^{+}$are different from 0 to increase the number of tuning parameters.

The open loop parameters are optimized in order to reduce the variation of the resonant peak $M_{\mathrm{T}}$ of the complementary sensitivity function $T(s)$. The following robustness cost function can be minimized:

$J=\left(M_{\mathrm{T}_{0}}-\inf _{G}\left|M_{\mathrm{T}}\right|\right)^{2}+\left(\sup _{G}\left|M_{\mathrm{T}}\right|-M_{\mathrm{T}_{0}}\right)^{2}$,

where $M_{\mathrm{T} 0}$ is a required value of the nominal closed loop resonant peak (for the nominal plant $G_{0}$ ), while respecting the following set of inequality constraints for all plants $G$ and for $\omega \in \mathbb{R}^{+}$:

$$
\begin{aligned}
& \inf _{G}|T(\mathrm{j} \omega)| \geq T_{1}(\omega), \sup _{G}|T(\mathrm{j} \omega)| \leq T_{\mathrm{u}}(\omega), \sup _{G}|S(\mathrm{j} \omega)| \leq S_{\mathrm{u}}(\omega) \\
& \sup _{G}|K S(\mathrm{j} \omega)| \leq K S_{\mathrm{u}}(\omega) \text { and } \sup _{G}|G S(\mathrm{j} \omega)| \leq G S_{\mathrm{u}}(\omega), \\
& \text { with }\left\{\begin{array}{l}
T(s)=\frac{G(s) K(s)}{1+G(s) K(s)} \quad S(s)=\frac{1}{1+G(s) K(s)} . \\
K S(s)=\frac{K(s)}{1+G(s) K(s)}
\end{array} \quad G S(s)=\frac{G(s)}{1+G(s) K(s)}\right.
\end{aligned}
$$

It is easy to show that the multiplicative uncertainty $\Delta_{\mathrm{m}} \beta(s)$ of the open-loop frequency response, which defines the frequency-domain uncertainty in the Nichols chart, is invariant and equal to that of the plant:

$\beta(s)=G(s) K(s)=G_{0}(s) \Delta_{\mathrm{m}} G(s) C(s)=\beta_{0}(s) \Delta_{\mathrm{m}} G(s)$

where $G_{0}(s)$ and $\beta_{0}(s)$ are the nominal plant and open-loop transfer functions and where $\Delta_{\mathrm{m}} G(s)$ (or $\Delta_{\mathrm{m}} \beta(s)$ ) is a multiplicative uncertainty model. Thus, the uncertainty frequency-domains related to the Nichols locus of $\beta_{0}(\mathrm{j} \omega)$ are defined by all the possible values of the ordered pair $\left(\arg \Delta_{\mathrm{m}} G(\mathrm{j} \omega),\left|\Delta_{\mathrm{m}} G(\mathrm{j} \omega)\right|_{\mathrm{dB}}\right)$. By minimizing $J$ (5), the optimal parameters position the uncertainty frequency domains so that they overlap as little as possible the low stability margin areas of the Nichols chart. As the uncertainties are taken into account by the least conservative method, only a a non-linear optimization method can be used.

For $N^{-}=N^{+}=0$, only four independent open-loop parameters have to be optimized. The parameterization of the open-loop transfer function by complex fractional orders, then simplifies the optimization considerably. During optimization a complex order has the same function as a whole set of parameters found in common rational controllers. Finally, the fractional controller $K_{\mathrm{F}}(s)$ is defined by its frequency response:

$$
K_{\mathrm{F}}(\mathrm{j} \omega)=\frac{\beta_{0}(\mathrm{j} \omega)}{G_{0}(\mathrm{j} \omega)} \text {. }
$$


The parameters of a rational (i.e. with integer orders) transfer function $K_{\mathrm{R}}(s)$ with a predefined low-order structure are tuned to fit the ideal frequency response $K_{\mathrm{F}}(\mathrm{j} \omega)$. Any frequency-domain system-identification technique can be used. An advantage of this design method is that whatever the complexity of the control problem, it can be used low values of the controller order (usually around 6).

\subsection{MIMO Crone design methodologies}

LTI square MIMO uncertain plants are often, for the sake of simplicity, controlled using diagonal (or decentralized) MIMO controllers. Each element of the controllers is usually designed by taking into account only SISO uncertain behaviors of the MIMO plants. When these SISO controllers are designed to achieve rapid dynamics, a decrease of the stability margins of each closed-loop can often be seen. Several Crone MIMO extensions have been defined for MIMO plants (Lanusse et al., 2000; Nelson-Gruel et al., 2008). The multi-SISO Crone control is defined as the SISO Crone control of each diagonal element of an uncertain $n \times n$ MIMO plant. The controller transfer matrix is diagonal and the coupling elements of plants are interpreted as an additional uncertainty on the plant diagonal elements.

A fully MIMO design approach may sometimes be necessary, for instance when the plant diagonal dominance degree is weak. Then, a MIMO Crone control design using diagonal or non-diagonal controllers has been proposed. The design of multi-SISO and MIMO Crone control relies on complementary approaches: the multi-SISO design is easy to use for MIMO plants, but is still a diagonal design; the MIMO design could be more efficient, but also more difficult to use. One or the other has to be chosen, depending on the multivariable degree of the plant, to optimize the ease-ofuse/performance trade-off.

\subsection{Multi-SISO Crone design methodology}

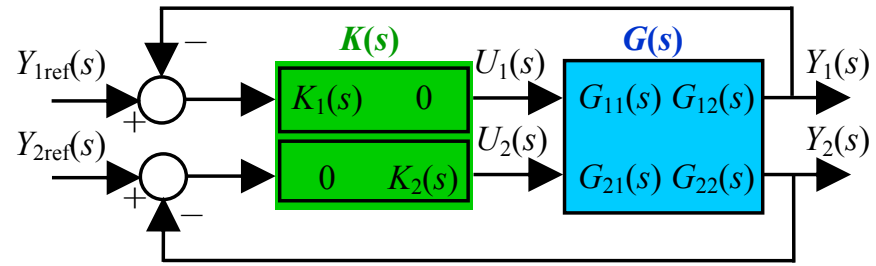

Fig. 3. Decentralized control of a 2x2 MIMO plant

The multi-SISO Crone approach enables the design of a decentralized controller $K(s)$ (Fig. 3). The open loop transfer function matrix $\beta(s)$ is

$\beta(s)=G(s) K(s)=\left[\begin{array}{ccc}K_{1}(s) G_{11}(s) & \cdots & K_{n}(s) G_{1 n}(s) \\ \vdots & \ddots & \vdots \\ K_{1}(s) G_{n 1}(s) & \cdots & K_{n}(s) G_{n n}(s)\end{array}\right]$.

The Gershgorin theorem states that the closed loop is stable if the -1 point of the complex plane is never included in circles with $\beta_{i i}(\mathrm{j} \omega)$ as center and $r_{i i}(\omega)$ as radius with:

$$
r_{i i}(\omega)=\min \left(\sum_{\substack{1 \leq j \leq n \\ \text { and } j \neq i}}\left|K_{j}(\mathrm{j} \omega) G_{i j}(\mathrm{j} \omega)\right|, \sum_{\substack{1 \leq j \leq n \\ \text { and } j \neq i}} \mid K_{i}(\mathrm{j} \omega) G_{j i}(\mathrm{j} \omega)\right)
$$

These circles can be taken into account as a new uncertainty that has to increase the uncertainty frequency-domains of $\beta_{i i}(\mathrm{j} \omega)$. They become ellipsoids on the Nichols chart if the plant is diagonal dominant. The corresponding multiplicative uncertainty is defined by:

$$
\min \left(1+\sum_{\substack{1 \leq j \leq n \\ \text { and } j \neq i}} \frac{\left|K_{j}(\mathrm{j} \omega) G_{i j}(\mathrm{j} \omega)\right|}{\left|K_{i}(\mathrm{j} \omega) G_{i i 0}(\mathrm{j} \omega)\right|}, 1+\sum_{\substack{1 \leq j \leq n \\ \text { and } j \neq i}} \frac{\left|G_{j i}(\mathrm{j} \omega)\right|}{\left|G_{i i 0}(\mathrm{j} \omega)\right|}\right)
$$

The second element related to the off-diagonal column elements remains unchanged when the controller is designed. Using the common SISO Crone approach, the design of each controller diagonal element $K_{i}(s)$ is achieved by taking into account:

- the diagonal nominal transfer function $G_{i i 0}(s)$

- the structured uncertainty computed from all possible values $G_{i i}(s)$

- the unstructured uncertainty computed from the offdiagonal elements $\mathrm{G}_{j i}(s)$ with $1 \leq j \leq n$ and $j \neq i$.

This approach enables an independent tuning of each open loop transfer function $\beta_{i}(s)$ (thus of each $K_{i}(s)$ ).

At each frequency, the construction of the multivariable uncertainty domains consists in the determination of the hull that takes into account both the uncertainty related to a perturbed diagonal element (SISO uncertainty domain) and the additional multivariable uncertainty (Fig. 4).

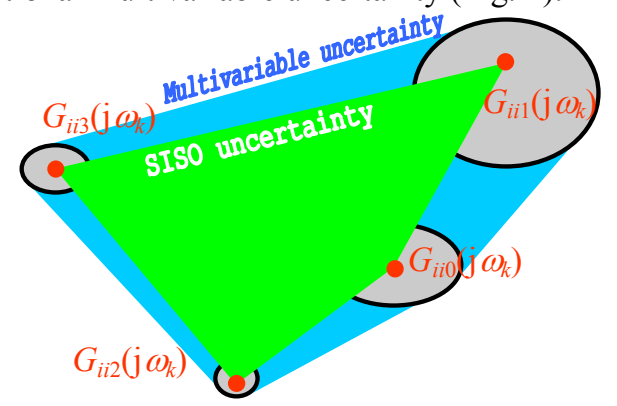

Fig. 4. Construction of multivariable uncertainty domains on the Nichols chart for 4 plant parametric states

\subsection{Non column-diagonal dominant plant, decentralized controller and multi-SISO design}

For non column-diagonal dominant plants (sum of off diagonal elements of each transfer function column which is not small compare to the diagonal element), the multivariable uncertainty presented by the previous section is large and cannot permit the design of a high-performing robust controller. Thus, a full MIMO design approach could be needed. Nevertheless if the plant is non diagonal dominant for one column only, the multi-SISO Crone approach can enables the design of a decentralized controller. For instance, let $G_{21}(s)$ of Fig. 3 be smaller than $G_{11}(s)$ (but $G_{12}(s)$ greater than $G_{22}(s)$. By using the multi-SISO approach, $K_{1}(s)$ can be designed by taking into account $G_{11}(s)$ and $G_{21}(s)$. Then, by using the SISO approach, $K_{2}(s)$ can be designed by taking into account the equivalent plant $G_{22}{ }^{*}(s)$ defined by: 


$$
G_{22}^{*}(s)=G_{22}(s)-\frac{G_{21}(s) K_{1}(s) G_{12}(s)}{1+K_{1}(s) G_{11}(s)} .
$$

\section{APPLICATION}

The considered engine is a PSA DW10ATED, which is a 2.0L turbocharged 4 cylinders engine with direct injection. All the air path actuators are pneumatic (wastegate, EGR and throttle). The Mean Value Engine Model (MVEM) 0D simulation model used here has been calibrated on our engine test bench. The simulation model is a non linear model based on physical equations (e.g. thermodynamic principles for volumes, Barré de St Venant equations for restrictions) and on look-up tables (e.g. volumetric efficiency, turbocharger) (Guzzella and Onder, 2004; Eriksson, 2007). All the simulation results shown here have been performed with LMS/AMESim.

\subsection{System identification}

Firstly, the operating points for identification must be chosen. The idea is to sweep operating point domain, and so the engine speed varies from $1000 \mathrm{rpm}$ to $4000 \mathrm{rpm}$ and the torque from minimum to maximum allowed in our engine test bench which corresponds to 54 operating points as shown in Fig. 5. Two excitations (EGR valve and wastegate) have been done to identify systems from EGR valve or wastegate to boost pressure or to air flow. Hence, four systems will be identified.

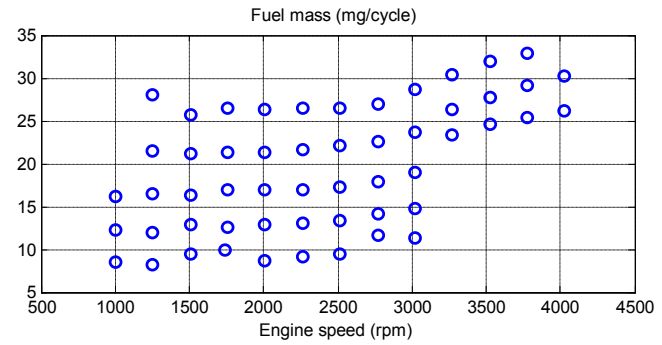

Fig. 5. Operating points used for identification

Secondly, the signal excitation must be chosen. Here, the sampling frequency is chosen to be of $1 \mathrm{kHz}$ and the exciting frequency goes from $0.2 \mathrm{~Hz}$ to $40 \mathrm{~Hz}$ according to the system dynamic. As the idea is to determine a frequency domain behavior, a multi-sine (i.e. a sum of sinusoids at different frequencies) or a chirp must be preferred to the PRBS (Pseudo Random Binary Signal). The advantage of the multisine (15) is that only a set of selected frequencies is included in the excitation signal:

$$
u(t)=u_{0}+\sum_{k=1}^{F} A \cos \left(2 \pi f_{k} t+\theta_{k}\right)
$$

where the Schroeder phases are $\theta_{k}=-k(k-1) \pi / F$ and $f_{k}$ is $l_{k} \mathrm{f}_{0}$ with $l_{k} \in \mathbb{N}$ and $F$ is the number of cosines.

Next, on each operating points of Fig. 5, signal excitation (with EGR valve and wastegate) is performed. The average $u_{0}$ and the amplitude $A$ are chosen with respect to the system constraints (i.e. saturation level), compromise between small signal hypothesis and noise level, and nominal value of the outputs. Some measurements like boost pressure or air flow are then acquired.
Finally, Fast Fourier Transform is performed to compute the Bode diagram matrix of the real system (Fig. 6). Four SISO transfer functions are described:

- $G_{11}$ : from EGR valve (\%) to air flow $(\mathrm{g} / \mathrm{s})$

- $G_{21}$ : from EGR valve (\%) to boost pressure (bar)

- $G_{12}$ : from wastegate (\%) to air flow $(\mathrm{g} / \mathrm{s})$

- $G_{22}$ : from wastegate (\%) to boost pressure (bar)

From these Bode diagrams, it can be noticed that the variation of frequency responses is important, so that the system is highly nonlinear. These nonlinearities will be taken into account in the controller design. It can be noticed that $\mathrm{G}_{11}$ is greater than $G_{21}$ but also that $G_{22}$ is lower than $G_{12}$. Thus, as explained by section $2.3, K_{1}(s)$ will be designed by using the multi-SISO approach and then, $K_{2}(s)$ will be designed by using the SISO approach on the equivalent plant $G_{22}{ }^{*}(s)$.
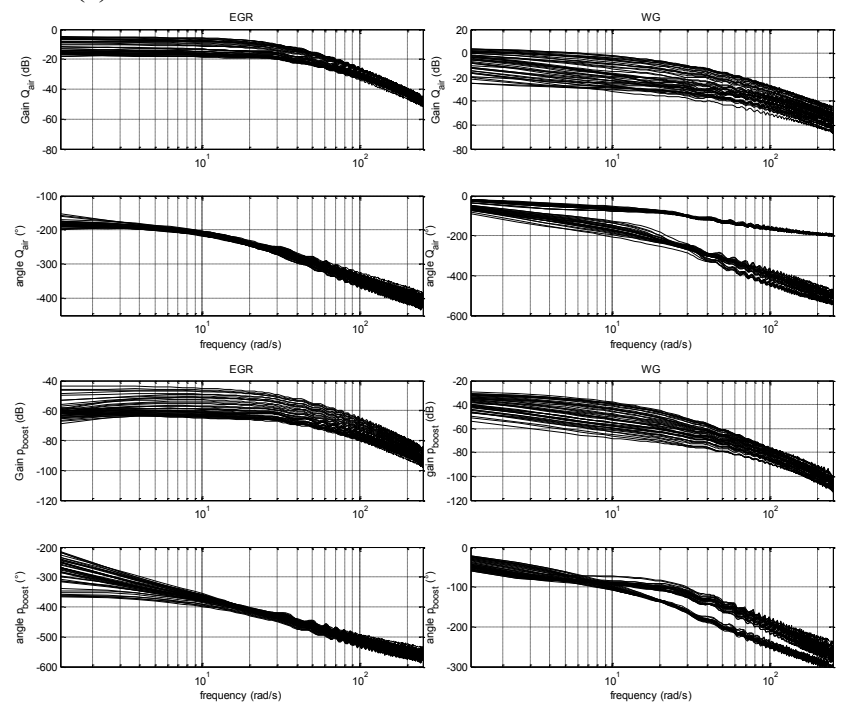

Fig. 6. Bode diagram of $G(\mathrm{j} \omega)=\left[\begin{array}{ll}G_{11}(\mathrm{j} \omega) & G_{12}(\mathrm{j} \omega) \\ G_{21}(\mathrm{j} \omega) & G_{22}(\mathrm{j} \omega)\end{array}\right]$

\subsection{Specifications}

For both controlled outputs, the first frequency-domain specifications, which are directly derived from the desired system dynamic, are a resonant peak of $T$ complementary sensitivity function lower than $1 \mathrm{~dB}$ (overshoot of $10 \%$ in order to ensure a sufficient stability degree) and a modulus margin greater than 0.5 (resonant peak of $S$ sensitivity lower than $6 \mathrm{~dB}$ ). The required value of the sensitivity function bandwidth is respectively $20 \mathrm{rad} / \mathrm{s}$ and $10 \mathrm{rad} / \mathrm{s}$ (response time $<0.15 \mathrm{~s}$ and $0.3 \mathrm{~s})$ for the $Q_{\text {air }}$ and $p_{\text {boost }}$ outputs. The acceptation of $3 \%$ of control noise for respectively $0.3 \mathrm{~g} / \mathrm{s}$ and 5 mbar of measurement noise needs to limit the $K S$ control effort sensitivity function at respectively $20 \mathrm{~dB}$ and $55.6 \mathrm{~dB}$. Note that a high frequency white noise is here considered.

\subsection{Control design}

Using the multi-SISO approach, the nominal open-loop transfer function $\beta_{10}(s)=G_{110}(s) K_{1}(s)$ is designed by taking into account perturbated $G_{11}(\mathrm{j} \omega)$ plus the additional unstructured uncertainty defined from $\left|G_{21}(\mathrm{j} \omega)\right| . G_{110}(s)$ is defined by an arbitrary transfer function whose frequency 
response is within the range of all the possible frequency responses. Then, using the SISO approach, $\beta_{20}(s)=$ $G_{220}{ }^{*}(s) K_{2}(s)$ is designed by taking into account $G_{22}{ }^{*}(s)$.

Both SISO systems $\left(\mathrm{EGR} \rightarrow \mathrm{Q}_{\mathrm{air}} G_{110}(s)\right.$ and equivalent $\left.\mathrm{WG} \rightarrow \mathrm{p}_{\text {boost }} G_{220}{ }^{*}(s)\right)$ have no integrator, so each controller must have an integrator to ensure zero steady state error (low gain at low frequency for $G S$ and $S$ sensitivity functions). Thus the low frequency order $n_{1 i}$ of each nominal fractional open loop needs to be 1 . To limit the control effort sensitivity at high frequency and to obtain a strictly proper controller, the high frequency order $n_{\mathrm{h} i}$ needs to be 4 for $\beta_{10}(s)$ and 5 for $\beta_{20}(s)$.

Figure 7 presents the optimized and perturbed open loop frequency responses.
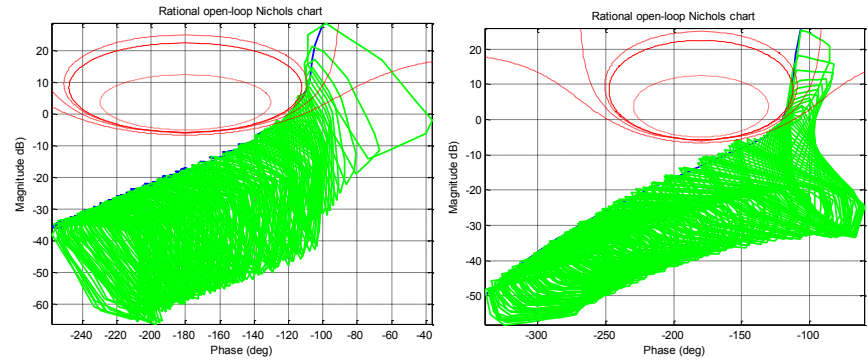

Fig. 7. Optimized open loop $\beta_{1}(s)$ for Air Flow control (left) and $\beta_{2}(s)$ for boost pressure control (right)

Using (9), a frequency domain system identification method provides the decentralized controller defined by:

$\left\{\begin{array}{l}K_{11}(s)=\frac{-0.008043 \mathrm{~s}^{3}-0.7022 \mathrm{~s}^{2}-16.72 \mathrm{~s}-59.57}{3.121 \mathrm{e}^{-6} \mathrm{~s}^{4}+0.002481 \mathrm{~s}^{3}+0.3375 \mathrm{~s}^{2}+\mathrm{s}} \\ K_{22}(s)=\frac{0.0001051 \mathrm{~s}^{5}+0.01397 \mathrm{~s}^{4}+0.7032 \mathrm{~s}^{3}+16.15 \mathrm{~s}^{2}+153.5 \mathrm{~s}+292.1}{5.096 \mathrm{e}^{-10} \mathrm{~s}^{6}+2.415 \mathrm{e}^{-7} \mathrm{~s}^{5}+4.338 \mathrm{e}^{-5} \mathrm{~s}^{4}+0.003573 \mathrm{~s}^{3}+0.124 \mathrm{~s}^{2}+\mathrm{s}}\end{array}\right.$

Figures 8, 9 present the closed-loop sensitivity functions $T$ and $K S$. Upper limits on the sensitivity functions are ensured.
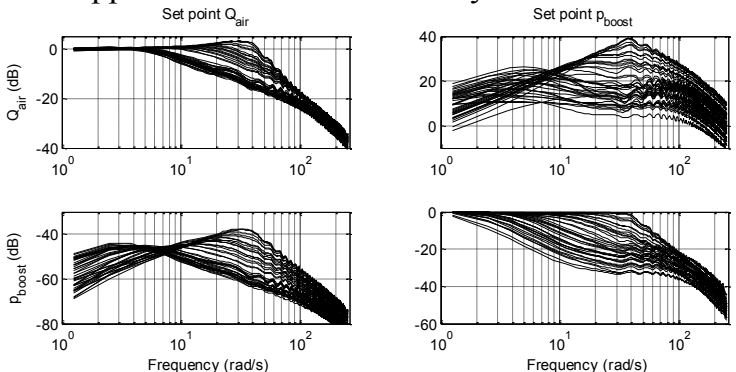

Fig. 8. Complementary sensitivity function $T$
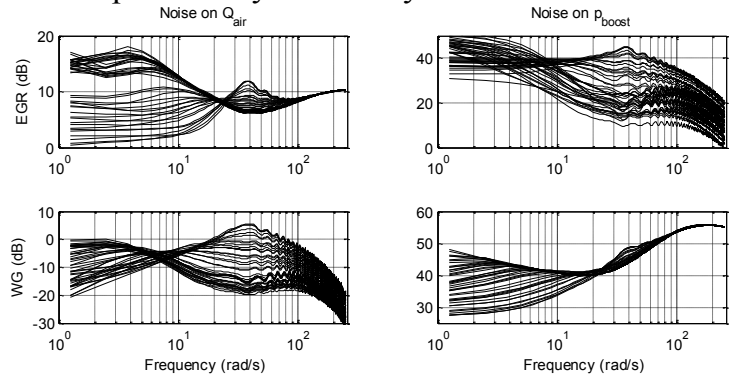

Fig. 9. Control effort sensitivity function $K S$

\section{SIMULATION RESULTS}

A classical Anti-Reset Windup (ARW) has been included to manage the saturation of the integrator as shown in Fig. 10. The range for the wastegate (resp. EGR) valve goes from $40 \%$ to $80 \%$ (resp. from $0 \%$ to $100 \%$ ). The controller is split into two parts, an integrator with one real zero and a transfer function (which is the other part of the controller):

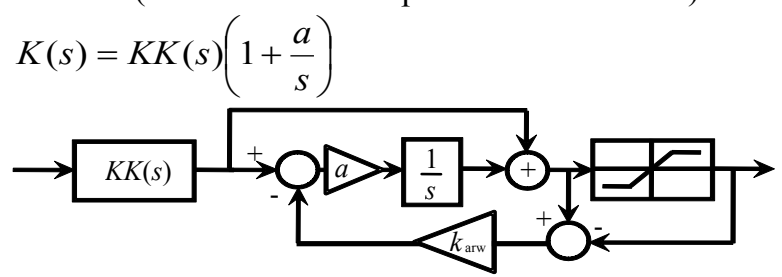

Fig. 10. Implementation of the Anti-Reset Windup

The control structure of Fig. 2 is used here, and the test scenario for the fuel mass is shown in Fig. 11.

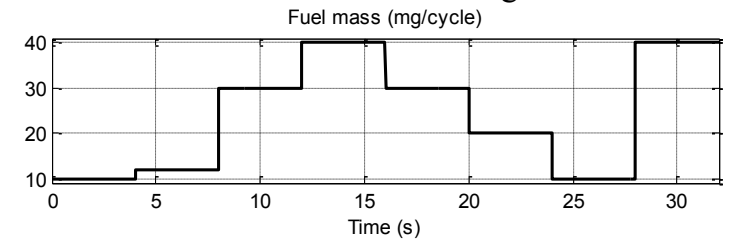

Fig. 11. Test scenario for fuel mass at $1500 \mathrm{rpm}$ and $2500 \mathrm{rpm}$

Both controllers are validated together in simulation on various transients. Figures 12 to 15 show two examples at two different engine speeds (1500 and $2500 \mathrm{rpm})$. The dynamic performance of both controllers is quite good. Indeed, only small overshoots are obtained and there is no steady state error. Figures 12 and 14 show the performance in terms of Air Flow and Figures 13 and 15 show the performance in terms of boost pressure. A prefilter on the set point could be added to decrease the overshoot (e.g Fig. 14 and 15). A static feedforward (learned from identification data) has been tested, but it does not increase the performance (e.g Fig. 12 and 13).

Finally, the proposed control scheme is compared to a decentralized linear Internal Model Control (IMC), as shown on Fig. 14 and 15. The internal model and the controller bandwidth are chosen the same as for the Crone design. The results show that the IMC is more oscillatory and has a behavior related to the nominal model chosen. Moreover, neither coupling, nor robustness and nor specifications (e.g. noise) are taken here into account with the IMC design.

\section{CONCLUSION}

In this paper, we propose a systematic method for designing a robust control, which we apply here to the air path of a diesel engine. The computationally inexpensive control is thus obtained faster than the usual look-up table based control. Indeed, after frequency-domain system identification, a multi-SISO Crone control is obtained ensuring all frequencydomain specifications. Good control performances of the proposed method have been demonstrated in simulation and compared to another control structure (Internal Model Control). Future works will extend this paper to more complex technologies (e.g. with throttle) and applied it on our engine test bench. Future works will have the global objective to obtain the best compromise NOx/PM. 


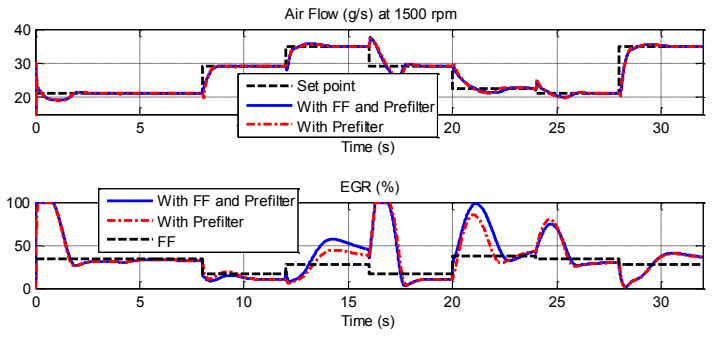

Fig. 12. Air flow (top in $\mathrm{g} / \mathrm{s}$ ) and EGR valve (bottom in \%) at $1500 \mathrm{rpm}$ with and without a feedforward
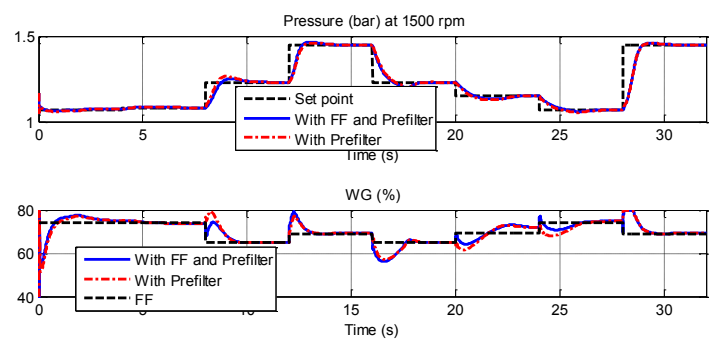

Fig. 13. Pressure (top in bar) and wastegate valve (bottom in $\%)$ at $1500 \mathrm{rpm}$ with and without a feedforward
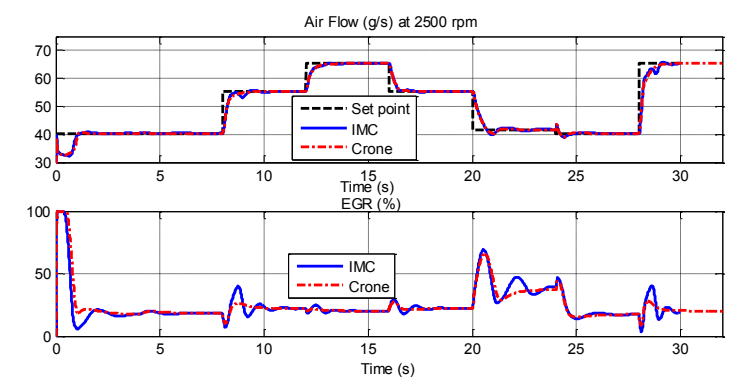

Fig. 14. Air flow (top in g/s) and EGR valve (bottom in \%) at 2500rpm. Comparison between Crone and IMC
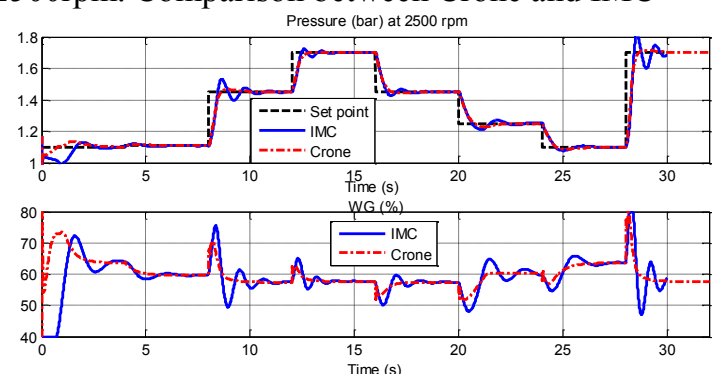

Fig. 15. Pressure (top in bar) and wastegate valve (bottom in $\%$ ) at $2500 \mathrm{rpm}$. Comparison between Crone and IMC.

\section{REFERENCES}

Åström, K.J. (1999), Model uncertainty and robust control design, Cosy Workshop - ESF Course, Valencia, Spain.

Chauvin, J., Corde G., Petit N., and Rouchon P. (2008), Motion planning for experimental airpath control of a Diesel HCCI engine, Control Engineering Practice, 16 (9), pp 1081-1091

Eriksson L. (2007), Modeling and Control of Turbocharged SI and DI Engines, Oil \& Gas Science and Technology Rev. IFP, 62 (4), pp. 523-538
García-Nieto S., Martínez M., Blasco X. and Sanchis J. (2008), Nonlinear predictive control based on local model networks for air management in diesel engines, Control Engineering Practice, 16 (12), pp 1399-1413

Guzzella, L. and Amstutz A. (1998). Control of Diesel Engines. IEEE Control Systems Magazine, 18 (5), pp. 53-71

Guzzella, L. and Onder C. (2004). Introduction to Modeling and Control of Internal Combustion Engine Systems. Springer.

Jung, M., Glover K. and Christen U. (2005), Comparison of uncertainty parameterisations for robust control of turbocharged diesel engines, Control Engineering Practice, 13 (1), pp 13-25.

Lanusse, P. (1994), De la commande CRONE de première génération à la commande CRONE de troisième generation. PhDThesis, Bordeaux I University, France.

Lanusse, P., A. Oustaloup, B. Mathieu (2000), Robust control of LTI square MIMO plants using two CRONE control design approaches, IFAC Symposium on Robust Control Design "ROCOND 2000", Prague, Czech Republic.

Nelson-Gruel, D., P. Lanusse, A. Oustaloup (2008), Decentralized CRONE control of mxn multivariable system with time-delay, 3nd IFAC Workshop on "Fractional Differentiation and its Applications" (FDA'08) - Ankara, Turquie.

Nitsche, R., Hanschke J., and Schwarzmann D. (2007), Nonlinear Internal Model Control of Diesel Air Systems, Oil \& Gas Science and Technology, 62 (4), pp. 501-512

Ortner, P. and del Re L. (2007). Predictive Control of a Diesel Engine Air Path, IEEE Transactions on Control Systems Technology, 15(3), pp 449-456

Oustaloup, A. (1983), Systèmes asservis linéaires d'ordre fractionnaire, Masson, Paris.

Oustaloup, A. (1991). La commande CRONE. Hermes Editor, Paris.

Oustaloup, A., B. Mathieu, P. Lanusse (1995), The CRONE control of resonant plants: application to a flexible transmission, European Journal of Control, Vol. 1, n 2 , pp. 113-121.

Van Nieuwstadt, M.J., Kolmanovsky I.V. et al., (2000). EGR-VGT control schemes: experimental comparison for a high-speed diesel engine. IEEE Control Systems Magazine, 20 (3), pp. 63-79.

Van Nieuwstadt, M., Moraal et al., (1998). Decentralized and multivariable designs for EGR-VGT control of a diesel engines. IFAC Advances in automotive control.

Wei, X. and del Re L. (2007). Gain Scheduled Hinf Control for Air Path Systems of Diesel Engines Using LPV Techniques, IEEE Transactions on Control Systems Technology, 15(3), pp 406-415

Wahlström, J. and Eriksson L. (2008). Robust Nonlinear EGR and VGT Control with Integral Action for Diesel Engines. Proceedings of the $17^{\text {th }}$ IFAC World Congress, Seoul, Korea. 